Research Article

\title{
Short-Term Air Quality Prediction Based on Fractional Grey Linear Regression and Support Vector Machine
}

\author{
Meng Dun, Zhicun Xu, Yan Chen $\mathbb{D}$, and Lifeng Wu $\mathbb{D}$ \\ School of Management Engineering and Business, Hebei University of Engineering, Handan 056038, China \\ Correspondence should be addressed to Lifeng Wu; wlf6666@126.com
}

Received 21 January 2020; Revised 7 April 2020; Accepted 2 May 2020; Published 18 May 2020

Academic Editor: Ana C. Teodoro

Copyright (c) 2020 Meng Dun et al. This is an open access article distributed under the Creative Commons Attribution License, which permits unrestricted use, distribution, and reproduction in any medium, provided the original work is properly cited.

To predict the daily air pollutants, the fractional multivariable model is established. The hybrid model of the grey multivariable regression model with fractional order accumulation model $(\operatorname{FGM}(0, \mathrm{~m}))$ and support vector regression model (SVR) is used to predict the air pollutants $\left(\mathrm{PM}_{10}, \mathrm{PM}_{2.5}\right.$, and $\left.\mathrm{NO}_{2}\right)$ from December 31, 2018, to January 3, 2019, in Shijiazhuang and Chongqing. The absolute percentage errors (APEs) are used to determine the weights of the $\operatorname{FGM}(0, \mathrm{~m})$ and SVR. Meanwhile, the HoltWinters model is used to predict the air quality pollutants for the same location and period. When the mean absolute percent error (MAPE) is $0 \%-20 \%$, it indicates that the model has good accuracy of fitting and prediction. The MAPE of the hybrid model is less than $20 \%$. It is shown that except for the $\mathrm{PM}_{2.5}$ concentration prediction in Shijiazhuang (13.7\%), the MAPE between the forecasting and actual values of the three air pollutants in Shijiazhuang and Chongqing was less than $10 \%$.

\section{Introduction}

According to the statistical data in China [1], the 338 cities had an average of $79.3 \%$ of days with good air quality (meet the air quality standard), which increased to $1.3 \%$ compared with 2017. The number of days with heavy pollution was 2.2 percent, which fell to $0.3 \%$ compared with 2017 . The $\mathrm{PM}_{2.5}$ concentration was $39 \mathrm{microgram} / \mathrm{m}^{3}$, which fell to $9.3 \%$ compared with 2017. The concentration of $\mathrm{PM}_{10}$ was 71 microgram $/ \mathrm{m}^{3}$, which fell to $5.3 \%$ compared with 2017 . The air quality in China improved in 2018 on a whole, but only 121 of 338 cities meet air quality standards as shown in Table 1. When the concentration of the air pollutants $\left(\mathrm{PM}_{10}\right.$, $\mathrm{PM}_{2.5}$, and $\mathrm{NO}_{2}$ ) meets the standard, the air quality is regarded as good. Otherwise, the air quality will be regarded as poor. The 24-hour air pollutant standard implemented since 2016 in China is shown in Table 1 [2]. In addition, there were 822 days of severe pollution, 20 more than that of 2017 . It indicates that the governance of air quality is still a problem that cannot be ignored.

In recent years, air quality has attracted more and more attention, and more and more research studies have been done on air quality. The impact of foreign direct investment and research as well as development on China's industrial $\mathrm{CO}_{2}$ emission reduction has been studied and its trend has been predicted [3]. A seasonal stacked autoencoder model combining seasonal analysis and deep feature learning was proposed for forecasting the hourly $\mathrm{PM}_{2.5}$ concentration in Beijing [4]. An integrated short-duration memory neural network was proposed for the prediction of hourly $\mathrm{PM}_{2.5}$ concentration in Beijing [5]. The trend of the observational $\mathrm{PM}_{10}$ concentrations in Shimla city, India, was analyzed [6]. The predictive models can be divided into two categories (single model and the hybrid model). Some scholars used a single model to study air quality, and the multigene genetic programming was used to predict the concentrations of $\mathrm{PM}_{10}$ [7]. The grey Markov model was used to predict the concentration of air pollutants in Pingdingshan [8]. A single dependent variable partial least squares regression was used to predict $\mathrm{PM}_{2.5}$ real-time concentration in Beijing [9]. The grey Holt-Winters Model was used to predict the air quality indexes of Shijiazhuang and Handan [10]. A microscale land use regression model was used to predict $\mathrm{NO}_{2}$ concentrations at a heavy trafficked suburban area in Auckland, NZ [11]. The seasonal grey one variable model with fractional order accumulation was used to predict air quality indexes of 
TABLE 1: 24-hour air pollutant standard (implemented since 2016 in China).

\begin{tabular}{lcc}
\hline & Meet the standard & Fail to meet the standard \\
\hline $\mathrm{PM}_{10}$ & $0 \sim 150 \mu \mathrm{g} / \mathrm{m}^{3}$ & $>150 \mu \mathrm{g} / \mathrm{m}^{3}$ \\
$\mathrm{PM}_{2.5}$ & $0 \sim 75 \mu \mathrm{g} / \mathrm{m}^{3}$ & $>75 \mu \mathrm{g} / \mathrm{m}^{3}$ \\
$\mathrm{NO}_{2}$ & $0 \sim 80 \mu \mathrm{g} / \mathrm{m}^{3}$ & $>80 \mu \mathrm{g} / \mathrm{m}^{3}$ \\
\hline
\end{tabular}

Xingtai and Handan [12]. The optimized particle swarm was used to predict the concentration of air pollutants in Aburrá Valley, Colombia [13]. The empirical mode decomposition based on the multifractal detrended fluctuation analysis method was used to study the daily $\mathrm{PM}_{2.5}$ concentration in Hong Kong [14]. A land use regression model was used to estimate annual and seasonal $\mathrm{PM}_{1}$, $\mathrm{PM}_{2.5}$, and $\mathrm{PM}_{10}$ concentrations [15]. Many scholars combined two different models to study the air quality, and the hybrid model of the regression models and feedforward backpropagation models with principle component analysis was used to predict the daily $\mathrm{PM}_{10}$ concentrations [16]. The mixed model of information gain and least absolute shrinkage was used to predict the air quality index [17]. A linear and an artificial neural network statistical model have been developed and validated and established to forecast the short-term $\mathrm{PM}_{10}$ hourly concentrations in the city of Brescia (Italy) [18]. The mixed air quality assessment model was designed and applied to analyze the pollution sources of $\mathrm{PM}_{2.5}$ [19]. A mixed forecasting model of daily air quality index considering air pollution factors in Beijing and Guilin was proposed [20]. A hybrid particle swarm optimizationsupport vector machine model based on clustering algorithm was used to forecast the short-term atmospheric pollutant concentration in Beijing [21]. A hybrid multiresolution multiobjective ensemble model was used to forecast the daily $\mathrm{PM}_{2.5}$ concentrations [22]. The hybrid model of autoencoder with bidirectional long short-term memory neural networks was used to predict the $\mathrm{PM}_{2.5}$ concentration [23].

In recent years, more and more hybrid models have been used by scholars to predict. However, few of them will use the hybrid model of the artificial intelligence algorithm and statistical algorithm and few scholars used the hybrid model to predict the air pollutants. It has been proved that the hybrid models with good prediction effect in M4 are the combination of artificial intelligence algorithm and statistical algorithm. In order to improve the prediction accuracy, a hybrid grey multivariable regression model with fractional order accumulation model [24] and support vector regression [25] model (FGM $(0, \mathrm{~m})-\mathrm{SVR})$ model is proposed to predict air pollutants $\left(\mathrm{PM}_{2.5}, \mathrm{PM}_{10}\right.$, and $\left.\mathrm{NO}_{2}\right)$ in this paper.

This paper is divided into five parts. In Section 2, the situation in Shijiazhuang and Chongqing is introduced. In Section 3, the hybrid model is introduced. In Sections 4 and 5, the process of calculation and the results of Shijiazhuang and Chongqing are shown, respectively. Through the analysis of the calculation results, some suggestions for the air quality in Shijiazhuang and Chongqing are given in Section 6. Meanwhile, the conclusions are summarized in Section 6.

\section{Location and Air Quality in Shijiazhuang and Chongqing}

2.1. Location in Shijiazhuang and Chongqing. Shijiazhuang is the capital city of Hebei Province. It is located in the north China plain, which is adjacent to Beijing and Tianjin in the north, Bohai in the east, Taihang Mountain in the west, and the economic zone in the south. Shijiazhuang is the gate of the capital city, 273 kilometers away from Beijing. It is located between latitude $37^{\circ} 27^{\prime} \sim$ $38^{\circ} 47^{\prime}$ and longitude $113^{\circ} 30^{\prime} \sim 115^{\circ} 20^{\prime}$ (as shown in Figure 1). Shijiazhuang is one of the most polluted cities in China. According to the statistics in 2018, Shijiazhuang ranked 168th among 169 cities with poor air quality in China.

Chongqing is an economic, financial, scientific, and technological innovation, shipping and commercial logistics center in the upper basins of the Yangtze River. It is located in the southwest of China's inland, Hubei and Hunan in the east, Guizhou in the south, Sichuan in the west, and Shanxi in the north. Chongqing is located longitude $105^{\circ} 17^{\prime} \sim 110^{\circ} 11^{\prime}$ and latitude $28^{\circ} 10^{\prime} \sim 32^{\circ} 13^{\prime}$ (as shown in Figure 1). Chongqing is also a heavily polluted city. Compared with previous years, the condition of air quality in Chongqing has improved significantly in 2019. But it is still a long way from the goal set by the Chongqing Ecology And Environment Bureau that ensures the number of days with good air quality in 2019 stays above 300. Chongqing has been known as "the city of fog" and the air quality ranks behind other cities in China.

2.2. Air Quality in Shijiazhuang and Chongqing. The number of days with good air quality (up to the air quality standard) as shown in Table 2 is obtained from the website of Shijiazhuang Environmental Protection Bureau (http://www. sjzhb.gov.cn) and Chongqing Environmental Protection Bureau (http://www.cepb.gov.cn/), respectively. The days with good air quality in Shijiazhuang and Chongqing from 2014 to 2018 can be seen from Figure 2 clearly.

As shown in Figure 2, despite the increasing efforts of government governance, the number of days with bad air quality had been increasing since 2015. According to the statistical data of the Hebei Province Environment Protection Hall in 2018, the air quality of Shijiazhuang is the worst in Hebei province. In addition, according to the statistics of China Environment Network, the air quality of Shijiazhuang was the worst among the 11 cities when it was ranked by air quality composite index. However, the target of air quality has been proposed in the "Three-year Action Plan for Shijiazhuang City to Win the Blue Sky Defense War (2018-2020)," and the days with good air quality in Shijiazhuang will exceed 176 days in 2019. It is mentioned in the plan that Shijiazhuang will complete the targets of "The 13th Five-year for Economic and Social Development of the People's obligatory" for air environmental quality until 2020, the main atmospheric pollutants emissions will be cut, and the rank of air quality strives to exit from the last 10 in 169 cities of China. Therefore, how to effectively predict the air quality is particularly important. 


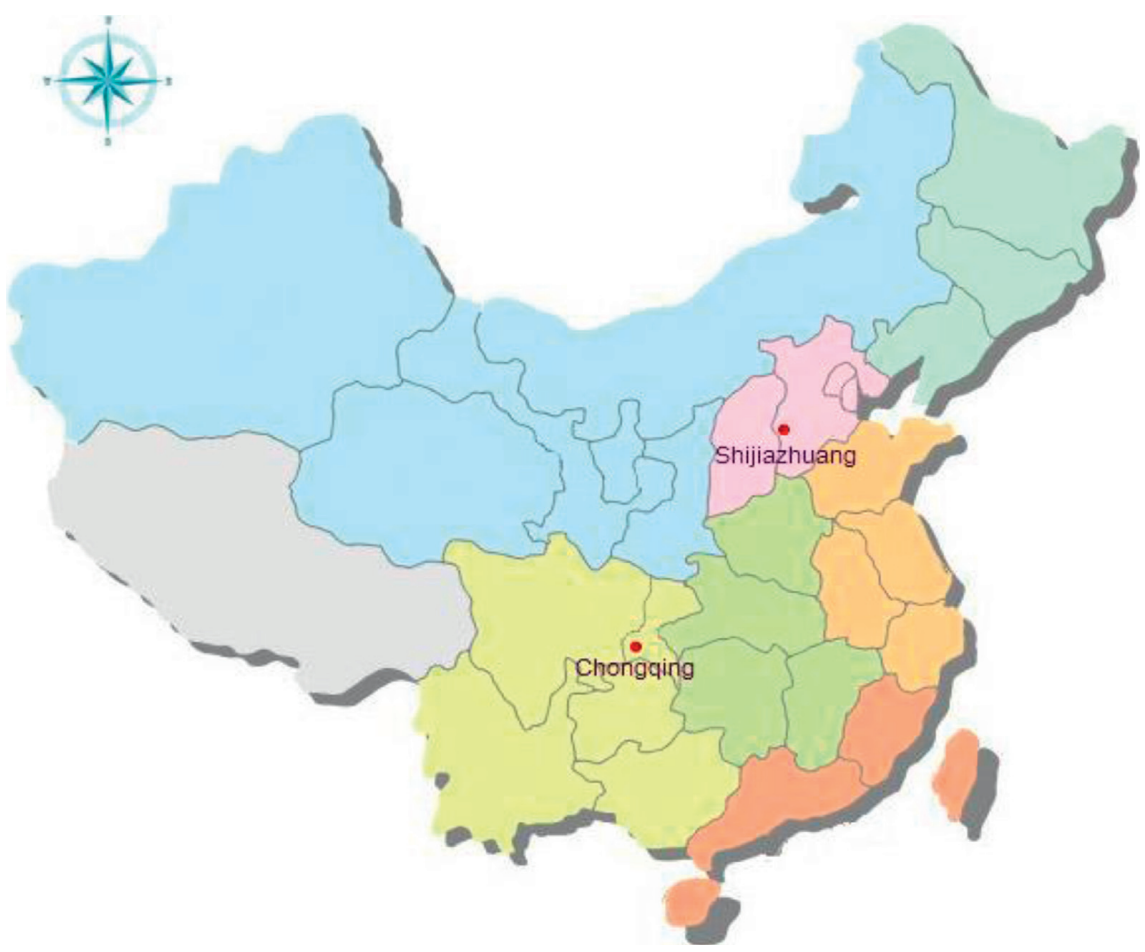

FIgURE 1: The geographical location of Shijiazhuang and Chongqing.

TABLE 2: Air quality standard.

\begin{tabular}{lc}
\hline Air quality index (unit: $\mu \mathrm{g} / \mathrm{m}^{3}$ ) & If up to standard \\
\hline $0-100$ & Up to standard \\
More than 100 & Not up to standard \\
\hline
\end{tabular}

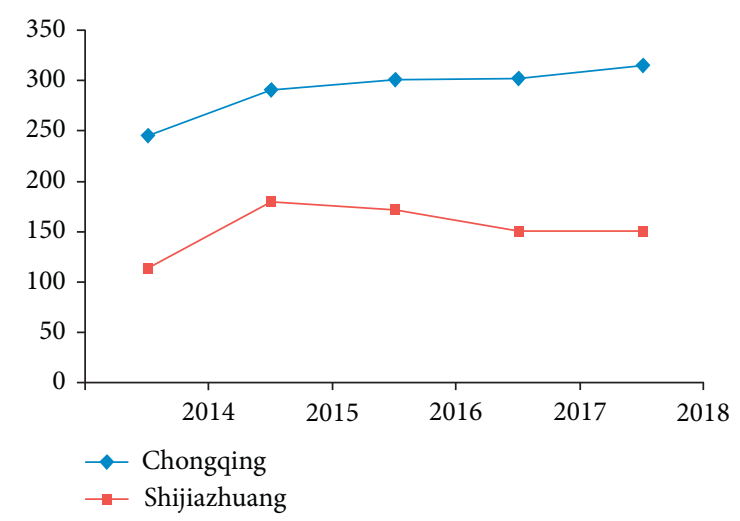

Figure 2: Days with good air quality in Shijiazhuang and Chongqing.

The number of days with heavy pollution in Chongqing is increasing year by year. The number of days with good air quality in Chongqing reached 316 in 2018. At the same time, the arrangements for the environmental protection work of 2019 had been made in the teleconference of Chongqing environmental protection on January 21, 2019: ensuring that the number of days with good air quality remains above 300 and that the average annual concentration of fine particulate matter is kept within 40 micrograms per cubic meter. From
2016 to 2018, the number of days with good air quality in Chongqing was 301,303 , and 316 , which is inseparable from the government's governance measures. If the air pollutant can be predicted more accurately, the air pollution control will be more effective.

\section{The Construction of Model}

By accumulating generation operators, the $\operatorname{FGM}(0, \mathrm{~m})$ model can transform the data from nonlinear to linear. At the same time, the data can be mapped from nonlinear to linear by using the SVR model. The historical parallelism was existed in the data of the same period. By processing the data through $\operatorname{FGM}(0, \mathrm{~m})$ and SVR, better accuracy of prediction will be achieved, so the $\operatorname{FGM}(0, \mathrm{~m})$ model and SVR model are used to forecast the air pollutants in this paper. In China, the number of people who choose to travel during the New Year's Day is larger, and people's travel is also affected by the environment, so it is particularly important to predict the air pollutants more effectively. Meanwhile, taking the air pollutant $\left(\mathrm{PM}_{10}\right)$ in Shijiazhuang as an example, the HoltWinters model is used to calculate the fitting and predictive values. The basis of the Holt-Winters model is that the time series with linear trend, seasonal change, and random fluctuation can be decomposed and combines with exponential smoothing method to establish a forecasting model. In recent years, the Holt-Winters model is often used to predict the seasonal data, and it was used to predict the air pollutants in Shijiazhuang and Handan [10]. The HoltWinters model was used to predict the air pollutant concentration $\left(\mathrm{PM}_{10}\right)$ in Shijiazhuang, and the results are contrasted with the hybrid model in this paper. 
3.1. The Model of $F G M(0, m)$. The $\operatorname{GM}(0, m)$ model has been widely used in recent years, and it was used to analyze the influence factor for the construction of the model in vocational high school [26]. The $\operatorname{GM}(0, \mathrm{~m})$ model was used to analyze the consumer experience on small- and mediumsized enterprises in creative living industry [27]. In this paper, the hybrid model of $\operatorname{FGM}(0, \mathrm{~m})$ and SVM is applied to predict air pollutants. The $\operatorname{FGM}(0, \mathrm{~m})$ model is introduced as follows:

$\mathrm{X}_{1}^{(0)}=\left(x_{1}^{(0)}(1), x_{1}^{(0)}(2), \cdots, x_{1}^{(0)}(n)\right) \quad$ is the system characteristics sequence.

$$
\begin{aligned}
\mathrm{X}_{2}^{(0)} & =\left(x_{2}^{(0)}(1), x_{2}^{(0)}(2), \cdots, x_{2}^{(0)}(n)\right), \\
\mathrm{X}_{3}^{(0)} & =\left(x_{3}^{(0)}(1), x_{3}^{(0)}(2), \cdots, x_{3}^{(0)}(n)\right), \\
& \vdots \\
\mathrm{X}_{m}^{(0)} & =\left(x_{m}^{(0)}(1), x_{m}^{(0)}(2), \cdots, x_{m}^{(0)}(n)\right),
\end{aligned}
$$

are the sequences of related factors.

Then,

$$
x_{j}^{(p / q)}(k)=\sum_{i=1}^{k} C_{k-i+((p / q)-1)}^{k-i} x_{j}^{(0)}(i)
$$

is the $p / q$ order accumulation generate operator. $C_{(p / q)-1}^{0}=1, C_{k}^{k+1}=0, k=0,1, \cdots, n-1$ :

$$
C_{k-i+((p / q)-1)}^{k-i}=\frac{(k-i+((p / q)-1)(k-i+((p / q)-2))) \cdots((p / q)+1)(p / q)}{(k-i) !}
$$

$X_{j}^{(p / q)}=\left(x_{j}^{(p / q)}(1), x_{j}^{(p / q)}(2), \cdots, x_{j}^{(p / q)}(n)\right)$ is the $p / q$ order accumulation sequence:

$$
\begin{aligned}
B & =\left[\begin{array}{cccc}
1 & x_{2}^{p / q}(1) & \cdots & x_{m}^{p / q}(1) \\
1 & x_{2}^{p / q}(2) & \cdots & x_{m}^{p / q}(2) \\
\vdots & \vdots & \vdots & \vdots \\
1 & x_{2}^{p / q}(n) & \cdots & x_{m}^{p / q}(n)
\end{array}\right], \\
Y & =\left[\begin{array}{c}
x_{1}^{p / q}(1) \\
x_{1}^{p / q}(2) \\
\vdots \\
x_{1}^{p / q}(n)
\end{array}\right], \\
{\left[a, b_{2}, \cdots, b_{m}\right]^{\mathrm{T}} } & =\left(B^{\mathrm{T}} B\right)^{-1} B^{\mathrm{T}} Y .
\end{aligned}
$$
by

Therefore, the equation of the $\operatorname{FGM}(0, \mathrm{~m})$ model is given

$$
\begin{aligned}
\widehat{x}_{1}^{(p / q)}(k)= & a+b_{2} x_{2}^{(p / q)}(k)+b_{3} x_{3}^{(p / q)}(k)+L+b_{n} x_{n}^{(p / q)}(k) \\
& \cdot(k=1,2, \cdots)
\end{aligned}
$$

where $a, b_{2}, b_{3}, \cdots, b_{m}$ are model parameters.

3.2. The Model of SVR. The SVR model is a linear separable model based on kernel functions that converts linearly indivisible data into high-dimensional space. In this paper, SVR model is used to learn the historical data, and according to the learning results, the model will make predictions. For the training sample set: $\left\{x_{j}^{(0)}(i), x_{1}^{(0)}(i)\right\}, j=2,3, \cdots, m$. $x_{j}^{(0)}(i), j=1,2, \cdots, m$ represents the input data of SVR, and $x_{1}^{(0)}(i)(i=n+1, n+2, \cdots)$ represents the output data of SVR. The function model of SVR is given by

$$
\widehat{x}_{1}^{(0)}=w^{\mathrm{T}} \varphi\left(x_{j}^{(0)}\right)+b \text {. }
$$

Among them, $\hat{x}_{1}^{(0)}$ represents predicted value, $\varphi(\bullet)$ represents a nonlinear mapping function, $w$ represents the weight vector, and $b$ is the bias. $w$ and $b$ give us the following formula:

$$
\begin{aligned}
& \min J=\frac{1}{2}|w|^{2}+C \sum_{i=1}^{n}\left(\zeta_{i}^{+}+\zeta_{i}^{-}\right), \\
& \text {s.t. }\left\{\begin{array}{l}
y_{i}-w^{\mathrm{T}} \varphi\left(x_{j}^{(0)}(i)\right)-b \leq \varepsilon+\zeta_{i}^{+}, \\
w^{T} \varphi\left(x_{j}^{(0)}(i)\right)+b-y_{i} \leq \varepsilon+\zeta_{i}^{-}, \\
\zeta_{i}^{+}, \zeta_{i}^{-} \geq 0, \quad i=1,2, \cdots, n ; j=1,2, \cdots, m,
\end{array}\right.
\end{aligned}
$$

where $C$ and $\varepsilon$ represent the maximum error coefficients of the penalty coefficient and insensitive loss function, respectively. $\zeta_{i}^{+}$and $\zeta_{i}^{-}$represent the relaxation coefficients. $n$ represents the sample size of input data.

The weight vector $w$ can be expressed as follows:

$$
w=\sum_{i=1}^{n}\left(\beta_{i}^{*}-\beta_{i}\right) \varphi\left(x_{j}^{(0)}(i)\right), \quad j=2,3, \cdots, m,
$$

where $\beta_{i}^{*}$ and $\beta_{i}$ represent Lagrange coefficient, respectively. The mathematical model equation of SVR is given by

$$
\widehat{y}_{2}=\sum_{i=1}^{n}\left(\beta_{i}^{*}-\beta_{i}\right) K\left(x_{1}^{(0)}(i), x_{j}^{(0)}(i)\right)+b
$$


where $K(\cdot)$ represents the kernel function for calculating the inner product of two input vectors in high-dimensional eigenvectors. The function of sigmoid is used in this paper.

3.3. The Basis of Model Weights. Through the statistical interpretation of multiple prediction models, a robust shortterm forecast of wind power generation under uncertainty is proposed [28]. A new method to determine the weight of the hybrid model is proposed. The root mean square errors (RMSEs) of model are used to determine the weight of the models. The RMSE is used as a performance index, which indicates the accuracy of the forecasting models due to awareness of RMSE over large errors in prediction. In this paper, the APEs are used to determine weights according to the same principle.

3.4. The Hybrid Model of $F G M(0, m)$ and SVR. In this paper, the fitting values and predictive values obtained by $\operatorname{FGM}(0$, $\mathrm{m})$ model and SVR model are given different weights, respectively. Then, the results obtained by the method described above are summed up, which is the final result. The calculation process is as follows:

$$
\begin{aligned}
\operatorname{APE}_{\mathrm{FGM}(0, \mathrm{~m})} & =\frac{\left|\widehat{x}_{\mathrm{FGM}(0, \mathrm{~m})}^{(0)}-x_{1}^{(0)}\right|}{x_{1}^{(0)}}, \\
\mathrm{APE}_{\mathrm{SVR}} & =\frac{\left|\widehat{x}_{\mathrm{SVR}}^{(0)}-x_{1}^{(0)}\right|}{x_{1}^{(0)}},
\end{aligned}
$$

where $\widehat{x}_{\mathrm{FGM}(0, \mathrm{~m})}$ is the forecasting value of the $\operatorname{FGM}(0, \mathrm{~m})$ model and $\widehat{x}_{S V R}$ is the forecasting result of the SVR model. $x_{1}^{(0)}$ is the actual values.

The weights of the two calculation results are divided, and then, the results are summed up:

$$
\begin{gathered}
\omega_{\mathrm{FGM}(0, \mathrm{~m})}=\frac{\mathrm{APE}_{\mathrm{FGM}(0, \mathrm{~m})}^{-1}}{\mathrm{APE}_{\mathrm{FGM}(0, \mathrm{~m})}^{-1}+\mathrm{APE}_{\mathrm{SVR}}^{-1}}, \\
\omega_{\mathrm{SVR}}=\frac{\mathrm{APE}_{\mathrm{SVR}}^{-1}}{\operatorname{APE}_{\mathrm{FGM}(0, \mathrm{~m})}^{-1}+\mathrm{APE}_{\mathrm{SVR}}^{-1}}, \\
\hat{x}_{1}^{(0)}=\omega_{\mathrm{FGM}(0, \mathrm{~m})} \times \hat{x}_{\mathrm{FGM}(0, \mathrm{~m})}^{(0)}+\omega_{\mathrm{SVR}} \times \hat{x}_{\mathrm{SVR}}^{(0)} .
\end{gathered}
$$

The APE is calculated between the final results and the actual values:

$$
\operatorname{APE}=\frac{\left|\widehat{x}_{1}^{(0)}-x_{1}^{(0)}\right|}{x_{1}^{(0)}}
$$

The MAPE from December 20 to 30 in 2018 is taken as the fitting error. The MAPE from December 31, 2018, to January 3,2019 , is taken as the predictive error. The process of modeling is shown in Figure 3.

\section{The Calculation Process and Results in Shijiazhuang}

In order to verify the accuracy of the hybrid model, three air pollutants in Shijiazhuang are used $\left(\mathrm{PM}_{10}, \mathrm{PM}_{2.5}\right.$, and $\left.\mathrm{NO}_{2}\right)$ from December 20 to January 3 between 2014 and 2017 and December 20 to December 30, 2018, as the samples for forecasting. The $\operatorname{FGM}(0, \mathrm{~m})$ model and the SVM model are used to predict the values from December 31 in 2018 to January 3 in 2019. According to equations (11)-(12), the weights of the $\operatorname{FGM}(0, \mathrm{~m})$ model and the SVM model are determined. Then, the calculated results of the $\operatorname{FGM}(0, \mathrm{~m})$ model and SVR model are multiplied by the above weights, respectively. According to equation (13), the fitting and forecasting values of the hybrid model can be obtained. The accuracy of the hybrid model is proved by calculating the MAPE between the final results and the actual values of the three models. The original data of the air pollutants are obtained from the website (http://www.airitilibrary.com/ Publication/alDetailedMesh?docid=10289488-201903-2019 03060025-201903060025-s19-28). There are eight monitoring stations, and seventeen monitoring stations have been set up in Shijiazhuang and Chongqing, respectively. According to the mean of the pollutant concentration in each monitoring station for a natural day (24 hours), the 24hour air pollutant concentration can be obtained.

\subsection{Calculation Results of $P M_{10}$}

4.1.1. Calculation Result of $P M_{10}$ by Using $\operatorname{FGM}(0, m)$ Model. Air quality has attracted more and more attention of the government in recent years. Since the meteorological indicators in the same historical period are similar, the meteorological conditions (favourable or unfavourable to pollutant dispersion) affect air quality, and similar meteorological condition generally affects air quality in a similar way. The governance measures and efforts of governments in the same region are not different from each other, and it accounts for that the air quality in the same region is also similar. The same period data (December 20 to January 3) from 2014 to 2017 are used as the independent variables $\left(X_{j}^{(0)}\right)$, and the data from December 20 to January 3, 2018, are used as the dependent variable $\left(X_{1}^{(0)}\right)$. Data of December 20 to December 30, 2018, are fitted and data of December 31, 2018, to January 3, 2019, are forecasted. The calculation process of $\mathrm{PM}_{10}$ in Shijiazhuang is taken as an example, and the original data of $\mathrm{PM}_{10}$ in Shijiazhuang is shown in Table 3.

$\operatorname{FGM}(0, \mathrm{~m})$ model is used to calculate the fitting values from December 20 to December 30, 2018, and the values from December 31, 2018, to January 3, 2019, are predicted. The calculation process is shown as follows.

$\operatorname{A~} \operatorname{FGM}(0,4)$ model is established:

$$
X_{1}^{(0)}=(215,153,228,132,193,248,114,78,68,79,122) \text {, }
$$




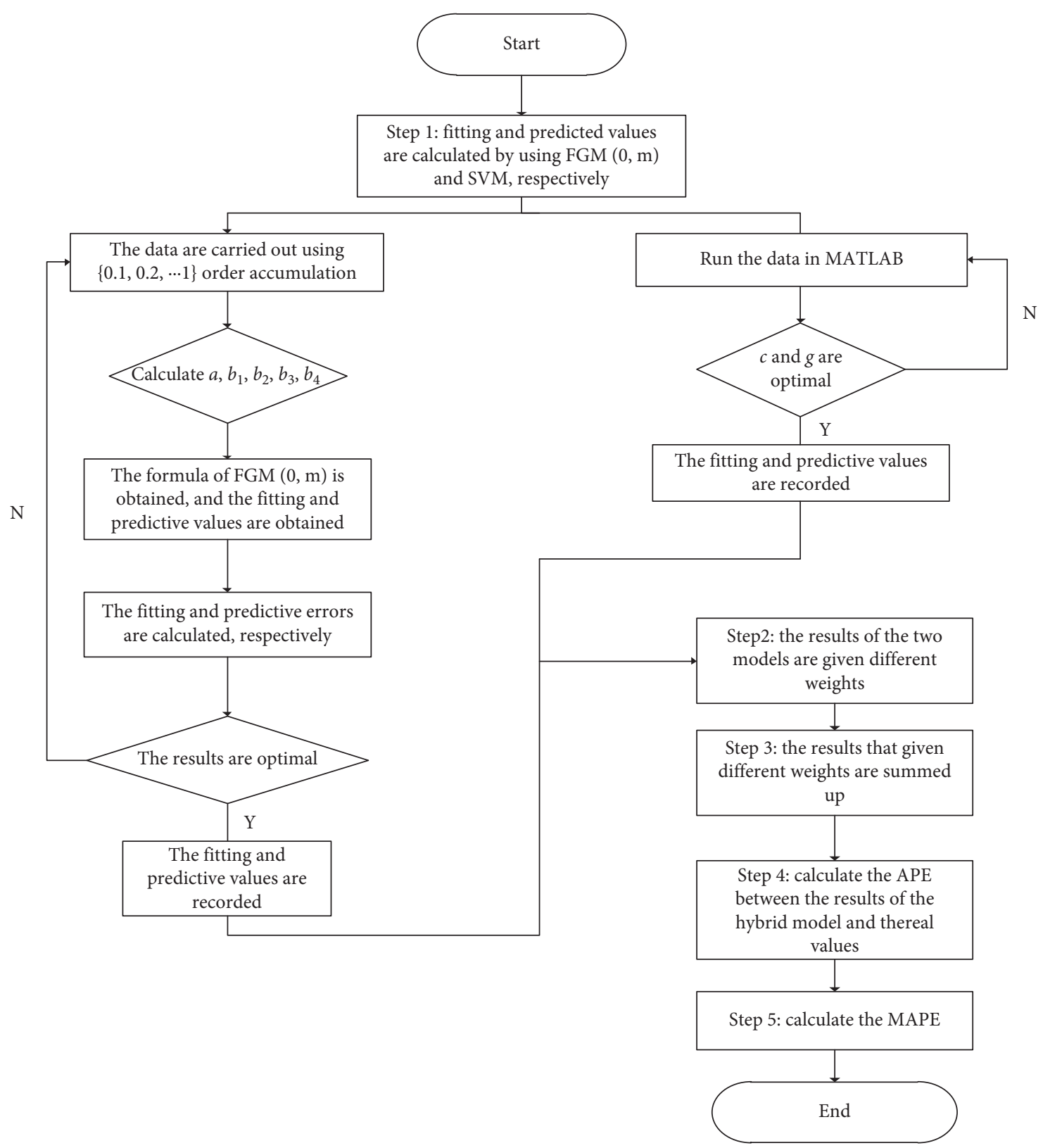

Figure 3: The process of modeling.

is the system characteristics sequence, and

$$
\begin{aligned}
& X_{2}^{(0)}=(87,97,108,333,237,191,353,478,237,218,192,122,156,220,358), \\
& X_{3}^{(0)}=(238,490,383,412,376,295,278,51,174,378,155,207,414,617,485), \\
& X_{4}^{(0)}=(866,765,181,142,258,282,298,170,342,308,413,710,617,493,471), \\
& X_{5}^{(0)}=(85,188,268,304,117,116,146,198,222,428,262,95,154,148,146),
\end{aligned}
$$


TABLE 3: Original data of $\mathrm{PM}_{10}$ (unit: $\mu \mathrm{g} / \mathrm{m}^{3}$ ) in Shijiazhuang.

\begin{tabular}{cccccc}
\hline & $X_{2}^{(0)}$ & $X_{3}^{(0)}$ & $X_{4}^{(0)}$ & $X_{5}^{(0)}$ & $X_{1}^{(0)}$ \\
& 2014 & 2015 & 2016 & 2017 & 2018 \\
\hline $12-20$ & 87 & 238 & 866 & 85 & 215 \\
$12-21$ & 97 & 490 & 765 & 188 & 153 \\
$12-22$ & 108 & 383 & 181 & 268 & 228 \\
$12-23$ & 333 & 412 & 142 & 304 & 132 \\
$12-24$ & 237 & 376 & 258 & 117 & 193 \\
$12-25$ & 191 & 295 & 282 & 116 & 248 \\
$12-26$ & 353 & 278 & 298 & 146 & 114 \\
$12-27$ & 478 & 51 & 170 & 198 & 78 \\
$12-28$ & 237 & 174 & 342 & 222 & 68 \\
$12-29$ & 218 & 378 & 308 & 428 & 79 \\
$12-30$ & 192 & 155 & 413 & 262 & 122 \\
$12-31$ & 122 & 207 & 710 & 95 & 200 \\
$01-01$ & 156 & 414 & 617 & 154 & 198 \\
$01-02$ & 220 & 617 & 493 & 148 & 273 \\
$01-03$ & 358 & 485 & 471 & 146 & 299 \\
\hline
\end{tabular}

are the sequences of related factors.

When $(p / q)=0.2$, the MAPE of $\operatorname{FGM}(0, \mathrm{~m})$ model is the smallest after the repeated experiments. Then, the system characteristic sequence and relevant factor sequence are carried out using 0.2-order accumulation, respectively; then

$$
\begin{aligned}
& x_{1}^{(0.2)}(1)=215.00, \\
& x_{1}^{(0.2)}(2)=196.00, \\
& x_{1}^{(0.2)}(3)=284.40, \\
& x_{1}^{(0.2)}(4)=214.88, \\
& x_{1}^{(0.2)}(5)=275.36, \\
& x_{1}^{(0.2)}(6)=345.99, \\
& x_{1}^{(0.2)}(7)=234.49, \\
& x_{1}^{(0.2)}(8)=187.92, \\
& x_{1}^{(0.2)}(9)=167.91, \\
& x_{1}^{(0.2)}(10)=172.23, \\
& x_{1}^{(0.2)}(11)=213.77 .
\end{aligned}
$$

Then,

$$
\begin{aligned}
Y & =(215,196,284.4,214.88,275.36,345.99,234.49,187.92,167.91,172.23,213.77)^{\mathrm{T}}, \\
B & =\left[\begin{array}{ccccc}
1 & 87 & 238 & 866 & 85 \\
1 & 114.4 & 537.6 & 938.2 & 25 \\
1 & 137.84 & 509.56 & 437.92 & 315.8 \\
\vdots & \vdots & \vdots & \vdots & \vdots \\
1 & 540.11 & 800.31 & 864.02 & 305.90
\end{array}\right]
\end{aligned}
$$

Thus,

$$
\begin{aligned}
{\left[a, b_{2}, b_{3}, b_{4}, b_{5}\right]^{\mathrm{T}} } & =\left(B^{\mathrm{T}} B\right)^{-1} B^{\mathrm{T}} Y \\
& =[8.789,0.156,0.478,0.003,-0.200]^{\mathrm{T}} .
\end{aligned}
$$
by

Therefore, the estimation equation of $\operatorname{FGM}(0,4)$ is given

$$
\begin{aligned}
\widehat{x}_{i}^{(0.2)}(k)= & 8.789+0.156 x_{2}^{(0.2)}(k)+0.478 x_{3}^{(0.2)}(k) \\
& +0.003 x_{4}^{(0.2)}(k)-0.200 x_{5}^{(0.2)}(k), \quad k=1,2, \cdots
\end{aligned}
$$

Therefore, the fitting values for $\mathrm{PM}_{10}$ from December 20 to December 30, 2018, and the forecasting values from December 31, 2018, to January 3, 2019, are shown in Table 4.

4.1.2. Calculation Result of $P M_{10}$ by Using SVR Model. In the research process of this paper, the firefly optimization algorithm and support vector regression model are established by using the toolkit in Matlab. The two parameters $C$ and $g$ of SVR method are optimized. In the process of selection, the optimal result can be obtained when the
MAPE between the actual values and the fitting values is the smallest. In this paper, the optimal results of $C$ and $g$ are $C=3.2103$ and $g=0.023268$, respectively. The kernel function sigmoid is used for learning. The optimal calculation results are obtained after the data are operated 50 times.

SVR is used to calculate the fitting values from December 20, 2018, to December 30, 2018, and the values from December 31, 2018, to January 3, 2019, are forecasted. In this paper, the data from December 20 to December 30 in 2014-2017 were used as the training set. Meanwhile, the data from December 31 to January 3 of the following year in 2014-2017 were used as the testing set. The MAPE was used as the standard to measure the effect of fitting. Taking the concentration of $\mathrm{PM}_{10}$ in Shijiazhuang as an example, the MAPE between the fitting values and the original data is $0.48 \%$. It can be seen that SVR has a good fitting effect and can be used for the forecasting of air pollutants. The calculation results are shown in Table 5.

4.1.3. Calculation Result of $P M_{10}$ by Using the Hybrid Model. According to equations (11)-(12), the weights are given to the calculation results obtained by the $\operatorname{FGM}(0, \mathrm{~m})$ model and SVR model, respectively: 
TABle 4: The results of $\operatorname{FGM}(0, \mathrm{~m})$ for $\mathrm{PM}_{10}$.

\begin{tabular}{lccc}
\hline & Actual value $\left(\right.$ unit: $\left.\mu \mathrm{g} / \mathrm{m}^{3}\right)$ & Predictive value $\left(\right.$ unit: $\left.\mu \mathrm{g} / \mathrm{m}^{3}\right)$ & APE $(\%)$ \\
\hline $12-20$ & 215 & 122 & 43.3 \\
$12-21$ & 153 & 223 & 156 \\
$12-22$ & 228 & 197 & 31.6 \\
$12-23$ & 132 & 203 & 49.2 \\
$12-24$ & 193 & 157 & 5.2 \\
$12-25$ & 248 & 168 & 36.7 \\
$12-26$ & 114 & 69 & 47.4 \\
$12-27$ & 78 & 86 & 11.5 \\
$12-28$ & 68 & 139 & 26.5 \\
$12-29$ & 79 & 62 & 75.9 \\
$12-30$ & 122 & & 49.2 \\
MAPE & & 110 & 38.4 \\
$12-31$ & 200 & 202 & 45.0 \\
$01-01$ & 198 & 310 & 2 \\
$01-02$ & 273 & 269 & 13.6 \\
$01-03$ & 299 & & 10 \\
MAPE & & & 17.7 \\
\hline
\end{tabular}

TABLE 5: The results of SVM for $\mathrm{PM}_{10}$.

\begin{tabular}{|c|c|c|c|}
\hline & Actual value (unit: $\mu \mathrm{g} / \mathrm{m}^{3}$ ) & Predictive value (unit: $\mu \mathrm{g} / \mathrm{m}^{3}$ ) & APE (\%) \\
\hline $12-20$ & 215 & 206 & 4.2 \\
\hline $12-21$ & 153 & 162 & 5.9 \\
\hline $12-22$ & 228 & 219 & 3.9 \\
\hline $12-23$ & 132 & 123 & 6.8 \\
\hline $12-24$ & 193 & 202 & 4.7 \\
\hline $12-25$ & 248 & 215 & 13.3 \\
\hline $12-26$ & 114 & 123 & 7.9 \\
\hline $12-27$ & 78 & 85 & 9 \\
\hline $12-28$ & 68 & 116 & 70.6 \\
\hline $12-29$ & 79 & 88 & 11.4 \\
\hline $12-30$ & 122 & 113 & 7.4 \\
\hline MAPE & & & 13.2 \\
\hline $12-31$ & 200 & 206 & 3 \\
\hline $01-01$ & 198 & 184 & 7.1 \\
\hline 01-02 & 273 & 161 & 41 \\
\hline $01-03$ & 299 & 134 & 55.2 \\
\hline MAPE & & & 26.6 \\
\hline
\end{tabular}

$$
\begin{aligned}
\hat{x}_{\mathrm{FGM}(0, \mathrm{~m})}^{(0)} & =122, \\
\hat{x}_{\mathrm{SVR}}^{(0)} & =206 .
\end{aligned}
$$

Thus,

$$
\begin{aligned}
\mathrm{APE}_{\mathrm{FGM}(0, \mathrm{~m})} & =\frac{\left|\hat{x}_{\mathrm{FGM}(0, \mathrm{~m})}^{(0)}-x_{1}^{(0)}\right|}{x_{1}^{(0)}}=\frac{|122-215|}{215}=43.256 \%, \\
\mathrm{APE}_{\mathrm{SVR}} & =\frac{\left|\hat{x}_{\mathrm{SVR}}^{(0)}-x_{1}^{(0)}\right|}{x_{1}^{(0)}}=\frac{|206-215|}{215}=4.186 \%, \\
\omega_{\mathrm{FGM}(0, \mathrm{~N})} & =\frac{\mathrm{APE}_{\mathrm{FGM}(0, \mathrm{~m})}^{-1}}{\mathrm{APE}_{\mathrm{FGM}(0, \mathrm{~m})}^{-1}+\mathrm{APE}_{\mathrm{SVR}}^{-1}}=\frac{43.256 \%^{-1}}{43.256 \%^{-1}+4.186 \%^{-1}}=0.09, \\
\omega_{\mathrm{SVR}(0, \mathrm{~m})} & =\frac{\mathrm{APE}_{\mathrm{SVR}}^{-1}}{\mathrm{APE}_{\mathrm{FGM}(0, \mathrm{~m})}^{-1}+\mathrm{APE}_{\mathrm{SVR}}^{-1}}=\frac{4.186 \%-1}{43.256 \% \%^{-1}+4.186 \%-1}=0.91 .
\end{aligned}
$$


Then, the predicted value of the hybrid model is given by

$$
\begin{aligned}
\hat{x}_{1}^{(0)}(12)= & \omega_{\mathrm{FGM}(0, \mathrm{~m})} \times \widehat{x}_{\mathrm{FGM}(0, \mathrm{~m})}^{(0)}+\omega_{\mathrm{SVR}} \times \widehat{x}_{\mathrm{SVR}}^{(0)}=0.09 \\
& \times 122+0.91 \times 206=198 .
\end{aligned}
$$

The APE of the hybrid model is given by

$$
\mathrm{APE}=\frac{\left|\widehat{x}_{1}(0)-x_{1}^{(0)}\right|}{x_{1}^{(0)}}=\frac{|198-215|}{215}=7.9 \% \text {. }
$$

Similarly, the fitting values of the hybrid model from December 20 to December 30, 2018, and the predicted values from December 31, 2018, to January 3, 2019, are shown in Table 5. Meanwhile, the comparison results between the hybrid model and the Holt-Winters model are shown in Table 6.

The MAPE of $\operatorname{FGM}(0, \mathrm{~m})$ is $38.4 \%$ and $17.7 \%$, respectively. The MAPE of SVR is $13.2 \%$ and $26.6 \%$, respectively. However, the MAPE of the hybrid model is $12.3 \%$ and $4.4 \%$, respectively. Although the fitting accuracy is improved slightly, the predictive accuracy is improved clearly. However, the MAPE of the hybrid model is relatively small, so the prediction effect of the hybrid model is better. The fitting and prediction accuracies of the hybrid model are $22.1 \%$ and $37.1 \%$ higher than those of the Holt-Winters model, respectively. It indicates that the fitting and prediction accuracies of the hybrid model are significantly higher than those of the Holt-Winters model.

4.2. Calculation Result of Hybrid Model for $P M_{2.5}$. It can be seen from Table 7 that the MAPE is $14.1 \%$ and $13.7 \%$, respectively. It can be seen that the MAPEs of the fitting values and prediction values of the hybrid model are all smaller, which indicates that the fitting accuracy and prediction accuracy are higher.

4.3. Calculation Results of $\mathrm{NO}_{2}$ by Using the Hybrid Model. According to the calculation results of Table 8, the MAPE for $\mathrm{NO}_{2}$ of the hybrid model is $12.4 \%$ and $2.3 \%$, respectively. The MAPE of the hybrid model is very small, and it indicates that both the fitting and prediction accuracies of the hybrid model are high.

\section{Calculation Results of the Air Pollutants in Chongqing}

Similarly, three pollutants of Chongqing $\left(\mathrm{PM}_{10}, \mathrm{PM}_{2.5}\right.$, and $\mathrm{NO}_{2}$ ) from December 20 to January 1 between 2014 and 2017, and December 20 to December 30, 2018, are used as samples for forecasting.

5.1. Calculation Result of $P M_{10}$ by Using Hybrid Model. In this paper, three pollutants $\left(\mathrm{PM}_{10}, \mathrm{PM}_{2.5}\right.$, and $\left.\mathrm{NO}_{2}\right)$ are predicted by using the hybrid model. The same method is used to verify that the hybrid model has higher accuracy than the $\operatorname{FGM}(0, \mathrm{~m})$ model and SVR model. The $\operatorname{FGM}(0, \mathrm{~m})$ model and SVR model are used to calculate the fitting values from
TABLE 6: The comparison results of the two models (unit: $\mu \mathrm{g} / \mathrm{m}^{3}$ ).

\begin{tabular}{lccc}
\hline & \multirow{2}{*}{ Actual value } & \multicolumn{2}{c}{ Predictive value } \\
& & Holt-Winters & The hybrid model \\
\hline $12-20$ & 215 & 120 & 198 \\
$12-21$ & 153 & 159 & 169 \\
$12-22$ & 228 & 97 & 212 \\
$12-23$ & 132 & 123 & 132 \\
$12-24$ & 193 & 102 & 202 \\
$12-25$ & 248 & 91 & 199 \\
$12-26$ & 114 & 111 & 129 \\
$12-27$ & 78 & 92 & 78 \\
$12-28$ & 68 & 100 & 94 \\
$12-29$ & 79 & 137 & 95 \\
$12-30$ & 122 & 105 & 106 \\
MAPE & & $34.4 \%$ & $12.3 \%$ \\
$12-31$ & 200 & 117 & 200 \\
$01-01$ & 198 & 138 & 198 \\
$01-02$ & 273 & 152 & 273 \\
$01-03$ & 299 & 150 & 247 \\
MAPE & & $41.5 \%$ & $4.4 \%$ \\
\hline
\end{tabular}

December 20 to December 30, 2018, and the predictive values from December 31, 2018, to January 1, 2019, respectively. The calculation results of the two models are multiplied by their weights, respectively. The results are shown in Table 9.

The MAPE of fitting and forecasting is $22.6 \%$ and $1.9 \%$, respectively. The MAPE of the forecasting values is small, which indicates that the prediction accuracy of the hybrid model is high.

5.2. Calculation Result of $P M_{2.5}$ by Using Hybrid Model. It can be seen from Table 10 that, for the hybrid model of $\operatorname{FGM}(0$, m) model and SVR model, the MAPE of fitting and forecasting is $9.5 \%$ and $3.4 \%$, respectively. The MAPE of the fitting and forecasting values is small, and it can be seen that the precision of the hybrid model has been significantly improved.

5.3. Calculation Result of $\mathrm{NO}_{2}$ by Using Hybrid Model. The hybrid model of the $\operatorname{FGM}(0, \mathrm{~m})$ model and SVR model is used to calculate the fitting values from December 20 to December 30, 2018, and the forecasting values from December 31, 2018, to January 3, 2019, respectively. As shown in Table 11, the fitting and prediction accuracies are $4.7 \%$ and $8.4 \%$, respectively. The fitting and prediction errors of the hybrid model are smaller. It indicates that the fitting and prediction accuracies of the hybrid model are higher. The error level of fitting and prediction is shown in Table 12.

According to the criteria mentioned above, the prediction accuracy of two air pollutants $\left(\mathrm{PM}_{10}\right.$ and $\left.\mathrm{NO}_{2}\right)$ in Shijiazhuang is $4.4 \%$ and $2.3 \%$, respectively. The prediction accuracy of three air pollutants $\left(\mathrm{PM}_{10}, \mathrm{PM}_{2.5}\right.$, and $\left.\mathrm{NO}_{2}\right)$ in Chongqing is $1.9 \%, 3.4 \%$, and $8.4 \%$, respectively. Although the prediction accuracy of $\mathrm{PM}_{2.5}$ is $13.7 \%$, the prediction accuracy appears to be in the relatively superior range. It indicates that the prediction accuracy of the hybrid model is relatively high. 
TABLE 7: The results of the hybrid model for $\mathrm{PM}_{2.5}$

\begin{tabular}{lccc}
\hline & Actual value $\left(\right.$ unit: $\left.\mu \mathrm{g} / \mathrm{m}^{3}\right)$ & Predictive value $\left(\right.$ unit: $\left.\mu \mathrm{g} / \mathrm{m}^{3}\right)$ & APE $(\%)$ \\
\hline $12-20$ & 134 & 124 & 7.5 \\
$12-21$ & 79 & 90 & 13.9 \\
$12-22$ & 138 & 128 & 7.2 \\
$12-23$ & 51 & 61 & 19.6 \\
$12-24$ & 90 & 99 & 10.0 \\
$12-25$ & 148 & 127 & 14.2 \\
$12-26$ & 66 & 66 & 0 \\
$12-27$ & 40 & 40 & 0 \\
$12-28$ & 33 & 48 & 45.5 \\
$12-29$ & 39 & 48 & 23.1 \\
$12-30$ & 72 & 62 & 13.9 \\
MAPE & & & 14.1 \\
$12-31$ & 142 & 131 & 7.7 \\
$01-01$ & 127 & 119 & 0.3 \\
$01-02$ & 182 & 182 & 0 \\
$01-03$ & 203 & 120 & \\
MAPE & & & 13.7 \\
\hline
\end{tabular}

TABLE 8: The results of the hybrid model for $\mathrm{NO}_{2}$.

\begin{tabular}{|c|c|c|c|}
\hline & Actual value (unit: $\mu \mathrm{g} / \mathrm{m}^{3}$ ) & Predictive value (unit: $\mu \mathrm{g} / \mathrm{m}^{3}$ ) & $\operatorname{APE}(\%)$ \\
\hline $12-20$ & 83 & 83 & 0 \\
\hline $12-21$ & 74 & 79 & 6.8 \\
\hline $12-22$ & 91 & 71 & 22.0 \\
\hline $12-23$ & 37 & 50 & 35.1 \\
\hline $12-24$ & 75 & 70 & 6.7 \\
\hline $12-25$ & 89 & 61 & 31.5 \\
\hline $12-26$ & 47 & 47 & 0 \\
\hline $12-27$ & 35 & 38 & 8.6 \\
\hline $12-28$ & 40 & 48 & 20.0 \\
\hline $12-29$ & 50 & 53 & 6 \\
\hline $12-30$ & 60 & 60 & 0 \\
\hline MAPE & & & 12.4 \\
\hline $12-31$ & 76 & 70 & 7.9 \\
\hline $01-01$ & 77 & 78 & 1.3 \\
\hline $01-02$ & 93 & 93 & 0 \\
\hline $01-03$ & 100 & 100 & 0 \\
\hline MAPE & & & 2.3 \\
\hline
\end{tabular}

Table 9: The results of the hybrid model for $\mathrm{PM}_{10}$.

\begin{tabular}{lccc}
\hline & Actual value $\left(\right.$ unit: $\left.\mu \mathrm{g} / \mathrm{m}^{3}\right)$ & Predictive value $\left(\right.$ unit: $\left.\mu \mathrm{g} / \mathrm{m}^{3}\right)$ & APE $(\%)$ \\
\hline $12-20$ & 130 & 123 & 5.4 \\
$12-21$ & 78 & 85 & 9.0 \\
$12-22$ & 90 & 69 & 23.3 \\
$12-23$ & 79 & 69 & 12.7 \\
$12-24$ & 56 & 56 & 0 \\
$12-25$ & 60 & 55 & 8.3 \\
$12-26$ & 56 & 49 & 12.5 \\
$12-27$ & 52 & 63 & 21.2 \\
$12-28$ & 34 & 62 & 82.4 \\
$12-29$ & 25 & 40 & 60.0 \\
$12-30$ & 49 & 42 & 14.3 \\
MAPE & & & 22.6 \\
$12-31$ & 57 & 57 & 0 \\
$01-01$ & 77 & 81 & \\
$01-02$ & 85 & 87 & \\
$01-03$ & 85 & 85 & \\
MAPE & & & 2.4 \\
\hline
\end{tabular}


TABLE 10: The results of the hybrid model for $\mathrm{PM}_{2.5}$

\begin{tabular}{lccc}
\hline & Actual value $\left(\right.$ unit: $\left.\mu \mathrm{g} / \mathrm{m}^{3}\right)$ & Predictive value $\left(\right.$ unit: $\left.\mu \mathrm{g} / \mathrm{m}^{3}\right)$ & APE $(\%)$ \\
\hline $12-20$ & 101 & 94 & 6.9 \\
$12-21$ & 61 & 67 & 9.8 \\
$12-22$ & 68 & 62 & 8.8 \\
$12-23$ & 58 & 54 & 6.9 \\
$12-24$ & 41 & 41 & 0 \\
$12-25$ & 45 & 41 & 8.9 \\
$12-26$ & 42 & 42 & 0 \\
$12-27$ & 41 & 42 & 2.4 \\
$12-28$ & 26 & 33 & 26.9 \\
$12-29$ & 21 & 27 & 28.6 \\
$12-30$ & 36 & 34 & 5.6 \\
MAPE & & & 9.5 \\
$12-31$ & 45 & 45 & 0 \\
$01-01$ & 57 & 61 & 7.0 \\
$01-02$ & 60 & 64 & 6.7 \\
$01-03$ & 63 & 63 & 3.4 \\
MAPE & & & \\
\hline
\end{tabular}

TABLE 11: The results of the hybrid model for $\mathrm{NO}_{2}$.

\begin{tabular}{|c|c|c|c|}
\hline & Actual value (unit: $\mu \mathrm{g} / \mathrm{m}^{3}$ ) & Predictive value (unit: $\mu \mathrm{g} / \mathrm{m}^{3}$ ) & APE (\%) \\
\hline $12-20$ & 55 & 53 & 3.6 \\
\hline $12-21$ & 51 & 49 & 3.9 \\
\hline $12-22$ & 42 & 37 & 11.9 \\
\hline $12-23$ & 42 & 42 & 0 \\
\hline $12-24$ & 42 & 42 & 0 \\
\hline $12-25$ & 41 & 39 & 4.9 \\
\hline $12-26$ & 36 & 38 & 5.6 \\
\hline $12-27$ & 34 & 35 & 2.9 \\
\hline $12-28$ & 32 & 37 & 15.6 \\
\hline $12-29$ & 27 & 28 & 3.7 \\
\hline $12-30$ & 32 & 32 & 0 \\
\hline MAPE & & & 4.7 \\
\hline $12-31$ & 33 & 31 & 6.1 \\
\hline $01-01$ & 38 & 38 & 0 \\
\hline $01-02$ & 43 & 40 & 7.0 \\
\hline $01-03$ & 39 & 31 & 20.5 \\
\hline MAPE & & & 8.4 \\
\hline
\end{tabular}

TABLE 12: The error level of fitting and prediction.

\begin{tabular}{lc}
\hline MAPE & Accuracy \\
\hline $0 \%-10 \%$ & High \\
$10 \%-20 \%$ & Good \\
$20 \%-30 \%$ & General \\
Exceed $30 \%$ & Bad \\
\hline
\end{tabular}

\section{Conclusions and Suggestions}

6.1. Suggestion for Shijiazhuang. In 2018, Shijiazhuang ranked 168th among 169 key cities with poor air quality in China, but this year, it plans to move out from the last 10 . The plan represents an effort to improve the atmosphere. Combined with the specific situation of Shijiazhuang, the suggestions are given from the following aspects:

(1) Firstly, as a city with a relatively dense population, Shijiazhuang should actively reduce the burden of the city and guide the transfer of population to surrounding counties and cities. This will not only reduce the pressure on the city, but also reduce the living pollution, traffic, and environmental pollution of Shijiazhuang.

(2) The transformation of the industrial structure should be accelerated, and the transformation of urban development should be promoted from heavy to light. In addition, "reduce the weight" of the city should be taken seriously. The transformation of industries from high-emission industries to emerging industries and environmental protection industries should be guided by the government actively.

6.2. Suggestion for Chongqing. As a city with developed tourism and economy, the annual pollution brought by tourism cannot be underestimated. Therefore, it is necessary 
to reduce the content of the pollutants in the air. Suggestions are given from the following aspects:

(1) Firstly, the main pollution should be cleaned up, such as dust pollution, coal pollution, and industrial pollution, which will lead to the increase of the pollutant content in the air and eventually lead to the decline of the air quality.

(2) Secondly, because of the developed tourism in Chongqing, the traffic pollution caused by the huge population flow cannot be ignored. In order to reduce air pollution, citizens and the public should be encouraged to take public transportation instead of private cars.

\section{Conclusions}

It has been proved that the hybrid model is of great research significance and practicability in the M4 competition in 2019. However, the hybrid models with good prediction effect in M4 are the combination of artificial intelligence algorithm and statistical algorithm. It is shown that the forecasting effect of the hybrid model $(\operatorname{FGM}(0, \mathrm{~m})-\mathrm{SVR})$ is better. The hybrid model is used to predict three air pollutants $\left(\mathrm{PM}_{10}, \mathrm{PM}_{2.5}\right.$, and $\left.\mathrm{NO}_{2}\right)$ in Shijiazhuang and Chongqing, and it is shown that the prediction accuracy of the hybrid model is significantly higher than that of the single model. The hybrid model can also be used to predict other air pollutants in other cities.

\section{Data Availability}

The data used in this study can be accessed via the website of Shijiazhuang Environmental Protection Bureau (http:// www.sjzhb.gov.cn) and Chongqing Environmental Protection Bureau (http://www.cepb.gov.cn/).

\section{Conflicts of Interest}

The authors declare that they have no conflicts of interest.

\section{Acknowledgments}

The relevant researches in this paper are supported by the National Natural Science Foundation of China (71871084), the Excellent Young Scientist Foundation of Hebei Education Department (SLRC2019001), and the Project of HighLevel Talent in Hebei Province.

\section{References}

[1] Asian Clean Air Centre, The Atmospheric Report in China of 2019, Asian Clean Air Centre, 2019.

[2] Ministry of Environmental Protection of the People's Republic of China, Ambient Air Quality Standards, Ministry of Environmental Protection of the People's Republic of China, Beijing, China, 2012.

[3] Y. Yang and W. Xu, "Impact of FDI and R\&D on China's industrial $\mathrm{CO}_{2}$ emissions reduction and trend prediction," Atmospheric Pollution Research, vol. 10, no. 5, pp. 1627-1635, 2019.
[4] Y. Bai, B. Zeng, C. Li, and J. Zhang, "An ensemble long shortterm memory neural network for hourly $\mathrm{PM}_{2.5}$ concentration forecasting," Chemosphere, vol. 222, pp. 286-294, 2019.

[5] Y. Bai, Y. Li, B. Zeng, C. Li, and J. Zhang, "Hourly $\mathrm{PM}_{2.5}$ concentration forecast using stacked autoencoder model with emphasis on seasonality," Journal of Cleaner Production, vol. 224, pp. 739-750, 2019.

[6] R. Ganguly, D. Sharma, and P. Kumar, "Trend analysis of observational $\mathrm{PM}_{10}$ concentrations in Shimla city, India," Sustainable Cities and Society, vol. 51, p. 101719, 2019.

[7] J. C. M. Pires, M. C. M. Alvim-Ferraz, M. C. Pereira, and F. G. Martins, "Prediction of $\mathrm{PM}_{10}$ concentrations through multi-gene genetic programming," Atmospheric Pollution Research, vol. 1, pp. 305-310, 2010.

[8] J. Yang and B. Sun, "Prediction of air pollutant concentration in Pingdingshan based on gray markov model," Journal of Mathematics in Practice and Theory, vol. 44, pp. 64-70, 2014.

[9] Z. Wang, X. Chen, and Q. Zhang, "Application of univariate PLS model in $\mathrm{PM}_{2.5}$ real-time concentration prediction," Computer Simulation, vol. 34, pp. 387-391, 2017.

[10] L. Wu, X. Gao, Y. Xiao, S. Liu, and Y. Yang, "Using grey HoltWinters model to predict the air quality index for cities in China," Natural Hazards, vol. 88, pp. 1003-1012, 2017.

[11] L. F. Weissert, J. A. Salmond, G. Miskell, M. Alavi-Shoshtari, and D. E. Williams, "Development of a microscale land use regression model for predicting $\mathrm{NO}_{2}$ concentrations at a heavy trafficked suburban area in Auckland, New Zealand," Science of The Total Environment, vol. 619-620, pp. 112-119, 2018.

[12] Q. Wu and H. Lin, "A novel optimal-hybrid model for daily air quality index prediction considering air pollutant factors," Science of The Total Environment, vol. 683, pp. 808-821, 2019.

[13] J. Murillo-Escobar, J. P. Sepulveda-Suescun, M. A. Correa, and D. Orrego-Metaute, "Forecasting concentrations of air pollutants using support vector regression improved with particle swarm optimization: case study in Aburrá Valley, Colombia," Urban Climate, vol. 29, Article ID 100473, 2019.

[14] C. Zhang, X. Wang, S. Chen, Le Zou, X. Zhang, and C. Tang, "A study on daily $\mathrm{PM}_{2.5}$ concentration in Hong Kong using the EMD-based MFDFA method," Physica A: Statistical Mechanics and Its Applications, vol. 530, Article ID 121182, 2019.

[15] M. Miri, Y. Ghassoun, A. Dovlatabadi, E. Ali, and M.-O. Löwner, "Estimate annual and seasonal $\mathrm{PM}_{1}, \mathrm{PM}_{2.5}$ and $\mathrm{PM}_{10}$ concentrations using land use regression model," Ecotoxicology and Environmental Safety, vol. 174, pp. 137-145, 2019.

[16] A. Z. Ul-Saufie, A. S. Yahaya, N. A. Ramli, N. Rosaida, and H. Abdul Hamid, "Future daily $\mathrm{PM}_{10}$ concentrations prediction by combining regression models and feedforward backpropagation models with principle component analysis (PCA)," Atmospheric Environment, vol. 77, pp. 621-630, 2013.

[17] B. Liu, H. Zheng, and B. Zhang, "Study on mixed prediction of air quality index based on IG-LASSO model," Environmental Science \& Technology, vol. 40, pp. 144-148, 2017.

[18] G. Gualtieri, F. Carotenuto, S. Finardi, M. Tartaglia, P. Toscano, and B. Gioli, "Forecasting $\mathrm{PM}_{10}$ hourly concentrations in northern Italy: insights on models performance and $\mathrm{PM}_{10}$ drivers through self-organizing maps," Atmospheric Pollution Research, vol. 9, pp. 1204-1213, 2018.

[19] H.-C. Lai, H.-W. Ma, C.-R. Chen, M.-C. Hsiao, and B.-H. Pan, "Design and application of a hybrid assessment of air quality models for the source apportionment of $\mathrm{PM}_{2.5}$," Atmospheric Environment, vol. 212, pp. 116-127, 2019. 
[20] K.-T. Wu, C.-S. Lai, M.-L. Shyu, and Chung-Jen, "Chin. Apply $\operatorname{GM}(0, N)$ to consumer experience on small and mediumsized enterprises in creative living industry," Journal of Grey System, vol. 3, pp. 55-60, 2019.

[21] S. Chen, J.-Q. Wang, and H.-Y. Zhang, "A hybrid PSO-SVM model based on clustering algorithm for short-term atmospheric pollutant concentration forecasting," Technological Forecasting \& Social Change, vol. 146, pp. 41-54, 2019.

[22] H. Liu, Z. Duan, and C. Chao, "A hybrid multi-resolution multi-objective ensemble model and its application for forecasting of daily $\mathrm{PM}_{2.5}$ concentrations," Information Sciences, vol. 516, pp. 266-292, 2020.

[23] B. Zhang, H. Zhang, G. Zhao, and J. Lian, "Constructing a $\mathrm{PM}_{2.5}$ concentration prediction model by combining autoencoder with Bi-LSTM neural networks," Environmental Modelling \& Software, vol. 124, Article ID 104600, 2020.

[24] L. Wu, S. Liu, L. Yao, S. Yan, and D. Liu, "Grey system model with the fractional order accumulation," Communications in Nonlinear Science and Numerical Simulation, vol. 18, pp. 1775-1785, 2013.

[25] C. Cortes and V. Vapnik, "Support-vector networks," Springer Journal, vol. 195, no. 20, pp. 273-297, 1995.

[26] D.-C. Wang and J.-R. Wang, "Appling $\operatorname{GM}(0, \mathrm{~N})$ model on the influence factor analysis for the construction of the model in vocational high school," Journal of Grey System, vol. 3, pp. 19-28, 2019.

[27] L. F. Wu, Nu Li, and T. Zhao, "Using the seasonal FGM $(1,1)$ model to predict the air quality indicators in Xingtai and Handan," Environmental Science and Pollution Research, vol. 26, pp. 14683-14688, 2019.

[28] N. Korprasertsak and T. Leephakpreeda, "Robust short-term prediction of wind power generation under uncertainty via statistical interpretation of multiple forecasting models," Energy, vol. 180, pp. 387-397, 2019. 